\title{
Pengembangan Modul Geometri Berbasis Pop Up Book dengan Berbalut Kebudayaan Lampung
}

\author{
Reka Damaiyanti ${ }^{1}$, Achi Rinaldi², Sri Purwanti Nasution ${ }^{3}$ \\ 1, 2, 3 Universitas Islam Negeri Raden Intan Lampung, J1 Kolonel H. Endro Suratmin, Lampung \\ rekadamaiyanti58@gmail.com
}

\begin{abstract}
Geometry learning becomes an interesting thing to develop as a learning tool in the form of pop-up book-based modules to see the interest of junior high school students towards learning mathematics, especially in geometry. The pop up book represents an image in 3-dimensional form, so that students can increase their interest in mathematics. Module development is carried out by paying attention to several aspects so that the module can be said to be suitable for use. Some of these aspects: quality of content, scope, language, and design Research objectives to see the attractiveness and feasibility of product modules produced in developing geometry generated in developing geometries produced in module development, and geometry based on pop up books in pop-up textiles. up books wrapped in Lampung culture. This study uses the R\&D method with the Borg and Gall Model using 7 steps out of 10 steps. The results of the assessment of the media validator and the material validator were categorized as "Very Appropriate" with a value of $86.11 \%$ and $87.50 \%$ respectively. The development of a popup book-based module wrapped in Lampung culture received a response from students with a proportion of $94 \%$ who were classified in the "Very Interesting" category.
\end{abstract}

Keywords: Module, Culture, Pop Up Book

\begin{abstract}
Abstrak
Pembelajaran Geometri menjadi hal menarik untuk dikembangkan sebagai alat pembelajaran berupa modul berbasis pop up book melihat kurangnya minat siswa sekolah menengah pertama terhadap pembelajaran matematika terutama pada pembelajaran geometri. Pop up book dapat merepresentasikan bentuk gambar dalam bentuk 3 Dimensi, sehingga siswa dapat meningkatkan minatnya terhadap pembelajaran matematika. Pengembangan modul dilakukan dengan memperhatikan beberapa aspek sehingga modul dapat dikatakan layak untuk digunakan. Beberapa aspek tersebut diantaranya: kualitas isi, ketepatan cakupan, bahasa, serta desain Tujuan Penelitian ini untuk mengetahui kemenarikan serta kelayakan produk modul yang dihasilkan dalam pengembanganmodul geometri berbasis pop up book dengan berbalut kebudayaan Lampung. Untuk mengetahui kelayakan produk modul yang dihasilkan dalam pengembanganmodul geometri berbasis pop up book dengan berbalut kebudayaan Lampung. Penelitian ini menggunakan metode R\&D dengan Model Borg and Gall menggunakan7 langkah dari 10 langkah yang ada. Adapun hasil Penilaian validator media dan validator materi tergolong kategori "Sangat Layak" dengan nilai masing-masing 86,11\% dan 87,50\%. Pengembangan modul dengan berbasis pop up book dengan berbalut kebudayaan Lampung memperoleh respon dari siswa dengan persentase 94\% yang digolongkan dalam kategori "Sangat Menarik.
\end{abstract}

Kata kunci: Modul, Kebudayaan, Pop Up Book

Copyright (c) 2021 Reka Damaiyanti, Achi Rinaldi, Sri Purwanti Nasution

$\triangle$ Corresponding author: Reka Damaiyanti

Email Address: rekadamaiyanti58@gmail.com (J1 Kolonel H. Endro Suratmin, Lampungcc)

Received 14 Desember 2020, Accepted 05 Februari 2021, Published 24 Maret 2021

\section{PENDAHULUAN}

Pekembangan di era 4.0 menimbulkan banyak perubahan terutama dalam pendidikan (Hasanah et al., 2019; Prasetyo \& Trisyanti, 2018; Priatmoko, 2018). Berbagai aspek kehidupan manusia juga ditopang oleh banyaknya ilmu pengetahuan (Gazali, 2018; Maftukhin, 2015), salah satunya matematika dan sebagai pengetahuan dasar dalam pengembangan penguasaan teknologi yang berperan penting (Romadon, 2020; Santiana et al., 2014; Winarso, 2014). Dengan hal tersebut menjadikan pemikiran manusia menjadikan matematika sebagai salah satu warisan budaya (Nugraha, 2019; Wahyuni et al., 
Pengembangan Modul Geometri Berbasis Pop Up Book dengan Berbalut Kebudayaan Lampung, Reka Damaiyanti, Achi Rinaldi, Sri Purwanti Nasution

2013). Selain itu, Sejarah perkembangan pun memperlihatkan sebuah kesinambungan yang terjadi pada matematika dan kehidupan masyarakat sehari-hari (Muhammad \& Nurdyansyah, 2015).

Pemikiran manusia akan membentuk matematika yang berkaitan dengan gagasan, metode, serta proses berpikir (Andinny, 2015; Irawaan, 2015; Winataputra et al., 2014). Teknologi mencari pemecahan berbagai permasalahan yang timbul dalam kegiatan bermasyarakat dan sebuah ilmu yang memiliki pemikiran deduktif (Amir, 2015; Nurfitriyanti, 2016; Winarso, 2014). Dalam setiap perkembangan zaman terdapat perkembangan menjadi manusia yang modern, Serta Manusia yang tidak dapat dipisahkan dari matematika sejak peradaban kuno hingga modern saat ini (Majid, 2019; Sujati, 2018). Sebagai salah satu pengetahuan eksak yang tersusun secara sistematis yang dapat membantu setiap lapisan masyarakat dalam menentukan sebuah gagasan dan menarik kesimpulan (Irvaniyah \& Akbar, 2014; Paradita \& Sukasno, 2016).

Perkembangan ilmu pengetahuan dan teknologi membutuhkan kompetensi matematika yang semakin hari terus meningkat, sehingga setiap manusia memiliki kesempatan dalam mengembangkan, menerima, mengoperasikan, serta memaksimalkan fungsi informasi (Hasanah, 2019; Zahara et al., 2017). Sebagai sarana yang menunjang kehidupan manusia yang berkompeten serta memiliki kualitas yang baik, pendidikan sangat dibutuhkan dan memiliki peranan yang sangat penting di dalamnya. Sebagai cerminan dari sebuah pendidikan suatu negara, maka sebuah mutu yang tinggi menjadi sangat penting. Sebagai penunjang sebuah pendidikan dibutuhkan fasilitas pendukung untuk menunjang sebuah pendidikan. Sebuah modul dikembangkan dan dibuat guna memfasilitasi pendidikan tersebut agar peserta didik diharapkan dapat belajar dengan mandiri dengan menyesuaikan metode dan dapat mengembangkan kemampuan peserta didik itu sendiri.(Permata, Fadila, and Fiteriani 2018; Rinaldi, Widyastuti, and Mardiah 2018).

Pengembangan bahan yang perlu dikembangkan khususnya dalam mata pelajaran bangun ruang sisi datar adalah modul berbasis pop up book yang memahami dalam sebuah gambar(Baiduri et al., 2019). Keanekaragaman suku bangsa di Indonesia melahirkan beragam kreasi intelektual yang diciptakan dalam sebuah kebudayaan sebagai ciri khas setiap daerah (Bashori, 2017; HERMAWAN \& Md, n.d.). Pop up book memberikan inovasi dalam penerapannya, Perpaduan antara geometri dengan pop up book Serta upakan sebuah inovasi dalam membantu para peserta didik dalam memahami materi geometri (Budiman, 2017; Setiawan et al., 2020). Selain itu, dengan membalutkan nya dengan ragam seni rupa budaya Lampung, diharapkan peserta didik dapat mengetahui bahwa banyak sekali bentuk geometri yang terdapat dalam ragam seni rupa budaya Lampung. Dengan adanya perpaduan ini menjadi bentuk salah satu melestarikan warisan leluhur budaya Lampung.

Penelitian mengenai pengembangan modul pop up book telah beberapa kali dikembangkan sebelumnya dilakukan para peneliti, diantaranya penelitiannya menghasilkan bahwa penggunaan pada modul pop up book (Halisah, 2018). Penelitian selanjutnya pada pengembangan modul berbasis pop up bookdengan terintegrasi ayat-ayat Alquran (Nurwahidah, 2018) Meskipun modul pop up booktelah banyak dikembangkan, namun terdapat perbedaan dalam setiap pengembangan yang akan 
dikembangkan oleh peneliti, diantaranya pengembangan modul iniberupa pembelajaran geometri; pengembangan modul ini dibalut dengan unsur-unsur kebudayaan Lampung, serta diharapkan pengembangan modul ini dapat membantu siswa dalam memahami mata pelajaran bangun datar sisi datar.

\section{METODE}

Penelitian ini menggunakan metode R\&D dengan Model Borg and Gall, dalam mengembangkan sebuah modul geometri dengan subyek penelitiannya adalah siswa kelas VIII sekolah menengah pertama (SMP) Negeri 1 Ambarawa, Lampung. Penelitian ini bermaksud untuk mengembangkan modul geometri pada materi bangun ruang sisi datar berbasis pop up book dengan berbalut kebudayaan Lampung. Pada pengembangan ini peneliti menggunakan 7 langkah dari 10 langkah yang terdapat pada metode Borg and Gall, diantaranya (Arifin, 2012) :

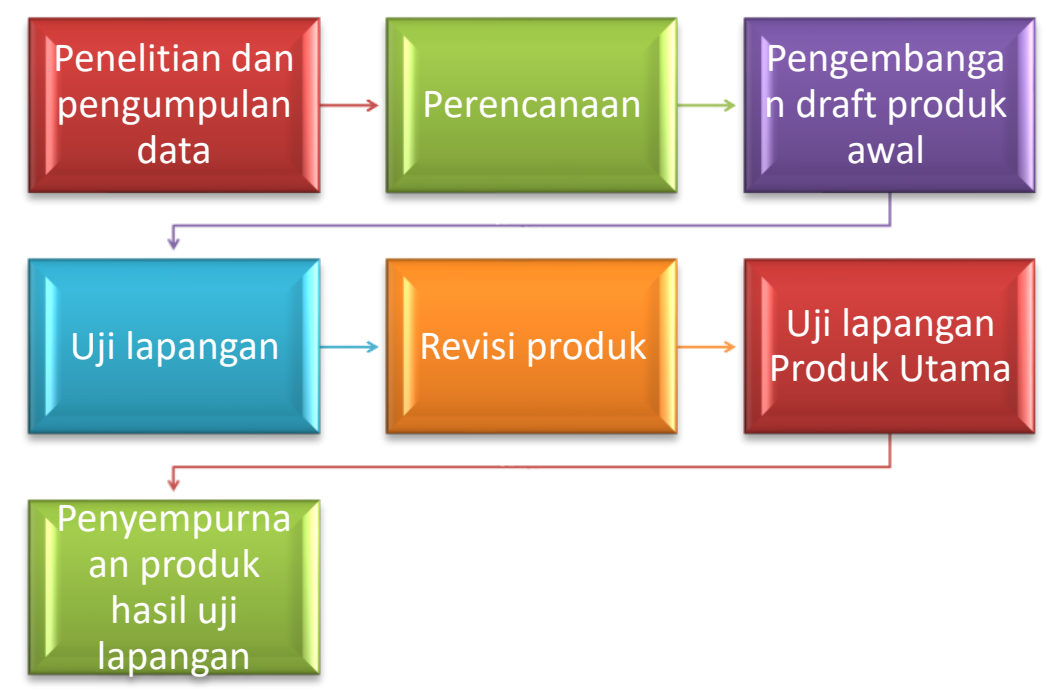

Gambar 1. Metode Borg and Gall

Pengumpulan informasi dijadikan sebuah acuan tentang sebuah hasil dari produk baru. Pengumpulan data diperoleh dari Analisis Awal. Pada tahap ini peneliti mencari informasi-informasi mendasar yang diperlukan dalam pengembangan modul (Hartono \& Noto, 2017). Pada tahap ini dengan perolehan hipotesis melalui masalah yang ada pada mata pelajaran geometri. Teknik Pengumpulan Data Penggunaan angket dilakukan guna memperoleh penilaian dari validator ahli dan siswa tentang penggunaan modul geometri berbasis pop up book dengan berbalut kebudayaan Lampung. Teknis Analisis Data dalam penelitian ini merupakan analisis deskriptif kualitatif Kuisioner responden diberikan kepada peserta didik guna mengumpulkan data terhadap produk yang sedang dikembangkan. Ketika pemberianpenilaian dilakukan, nilai tengah dicari kemudian dinyatakan dalam bentuk sebuah pertanyaan guna mengetahui seberapa menarik produk pengembangan tersebut. 
Pengembangan Modul Geometri Berbasis Pop Up Book dengan Berbalut Kebudayaan Lampung, Reka Damaiyanti, Achi Rinaldi, Sri Purwanti Nasution

\section{HASIL}

Hasil dari penelitian dan pengembangan yang telah dilakukan menggunakan metode Borg \& Gall. Menurut Borg \& Gall pada tingkatan S1, mahasiswa semestinya melakukan pengembangan dengan skala kecil dengan mempertimbangkan sumber daya yang dimiliki masih terbatas. Melaui pernyataan tersebut pertimbangan terhadap pembatasan langkah-langkah dalam proses penelitian dan pengembangan yang akan dilakukan(Borg \& Gall, 2003). Penelitian dan pengembangan dengan metode Borg \& Gall memiliki 10 langkah, namuin dalam penelitian ini hanya menggunakan 7 langkah dari 10 langkah, di antaranya:

\section{Penelitian dan Pengumpulan Data (Research and Informatioan Collect)}

Pengumpulan data bersumber dari hasil pra penelitian di SMP N 1 Ambarawa, Pringsewu yang dilakukan guna mengetahui kebutuhan siswa. Dalam hal ini siswa membutuhkan bahan ajar yang dapat membuat siswa tidak bosan dengan pembelajaran matematika khususnya pada sub bab bangun datar.

\section{Perencanaan (Planning)}

Perencanaan dilakukan menyesuaikan dengan kompetensi dasar K-13 pada isi. Kemudian diasiapkan alat dahan bahan untuk mengembnagkan modul, serta menyusun angket validasi serta angket penilaian peserta didik.

\section{Pengembangan Draft Produk Awal (Develop Preliminary Form Of Product)}

Spesifikasi dari pengembangan dengan berbasis pop up book yang berbentuk 3D memiliki alat dan bahan yang tidak sulit didapatkan sehingga proses pembuatan tidak terhambat. Pembuatan desain menggunakan program microsoft word 2010 dan photoshop CS3 serta kertas yang digunakan menggunakan kertas Art Paper, mika kaku pada bagian bangun ruang yang akan dibentuk pop up, dan karton jepang untuk bagian sampul. Pada tahap ini jenis pop up yang digunakan ada dua jenis yaitu box and cylinder dan internal stand.
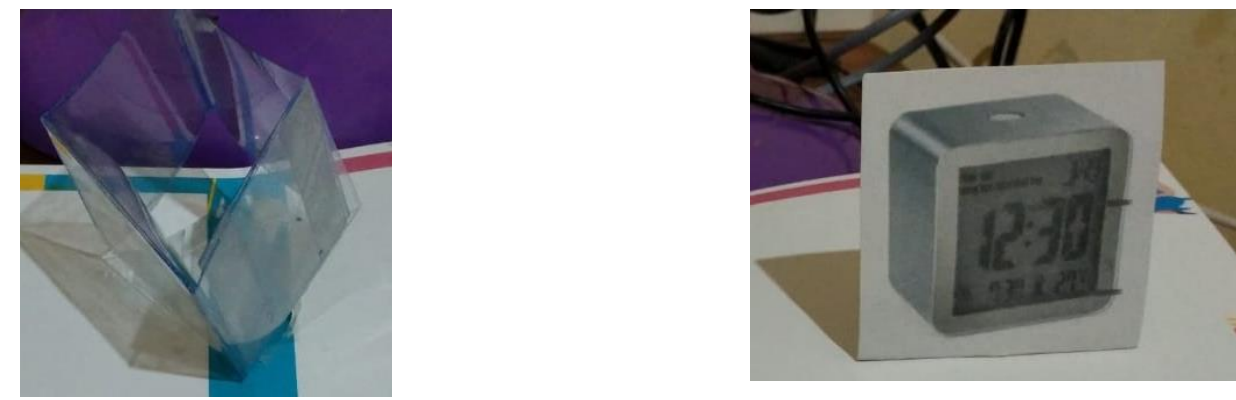

Gambar 2. Box and Cylinder dan Internal Stand

\section{Uji Lapangan Produk Awal (Preliminary Field Testing)}

Modul yang telah dikembangkan di uji kelayakannya melalui validasi produk. Validasi yang akan dilakukan terhadap modul yang dikembangkan yaitu validasi ahli materi dan media. Aspek yang dinilai oleh para validator materi diantaranya yaitu kualitas isi, ketepatan cakupan serta bahasa. Berikut hasil validasi tahap 1 oleh ahli materi dan ahli media. 

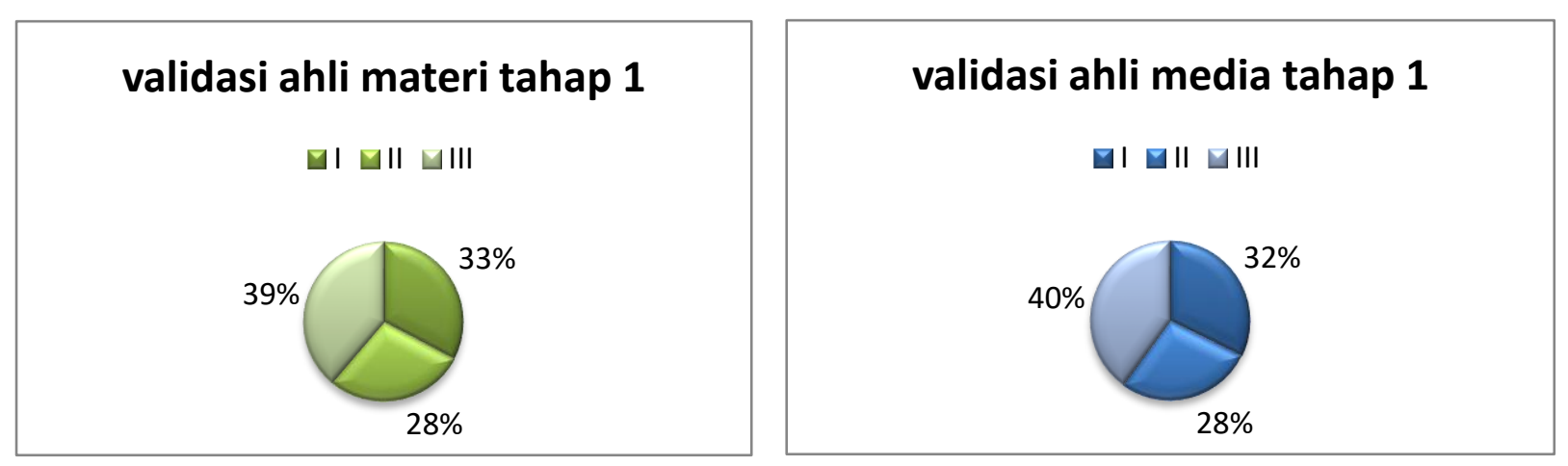

Gambar 3. Diagram validasi ahli materi dan media tahap I

Berdasarkan tabel diatas menunjukkan hasil validasi tahap 1 oleh ahli materi mendapatkan persentase sebesar 77,89\% pada kelayakan ini mempunyai kriteria "layak" dengan saran perbaikan berupa penambahan pengetahuan terhadap kebudayaan Lampung pada modul dan pada validasi oleh ahli media diperoleh persentase sebesar 80,73\% dengan kriteria "layak" dengan saran perbaikan untuk dapat mengganti bahan mika kaku diganti dengan kertas art paper serta mengganti jenis pop up internal stand diganti dengan v-folding.

\section{Revisi Produk Awal (Main Product Revision)}

Pada tahap ini atas saran dari para ahli maka dilakukan revisi. Saran yang diberikan oleh ahli untuk menambahkan pengetahuan terhadap kebudayaan lampung pada modul yang dikembangkan.
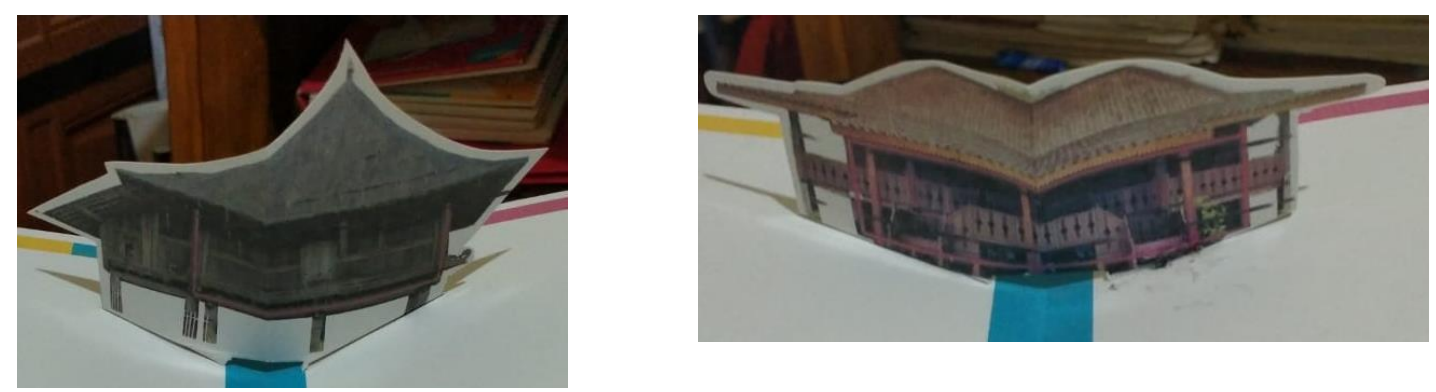

Gambar 4. Rumah Adat Lampung

Kemudian saran dari ahli media untuk mengganti mika kaku dengan kertas art paper gsm 260 untuk jenis pop up box and cylinder.
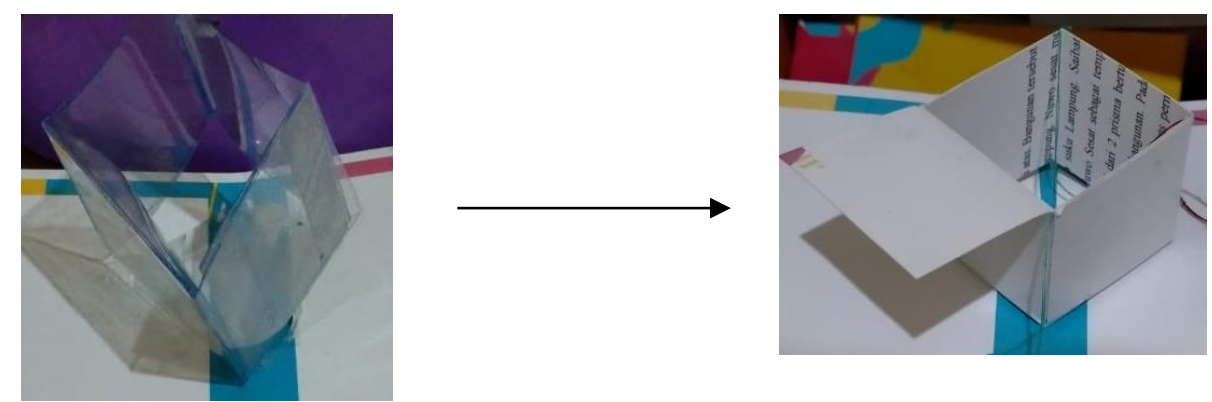

Gambar 6. Bahan mika kaku diganti dengan kertas Art Paper Gsm 260 
Selanjutnya jenis pop up internal stand diganti dengan jenis v-folding atas saran dari ahli media.
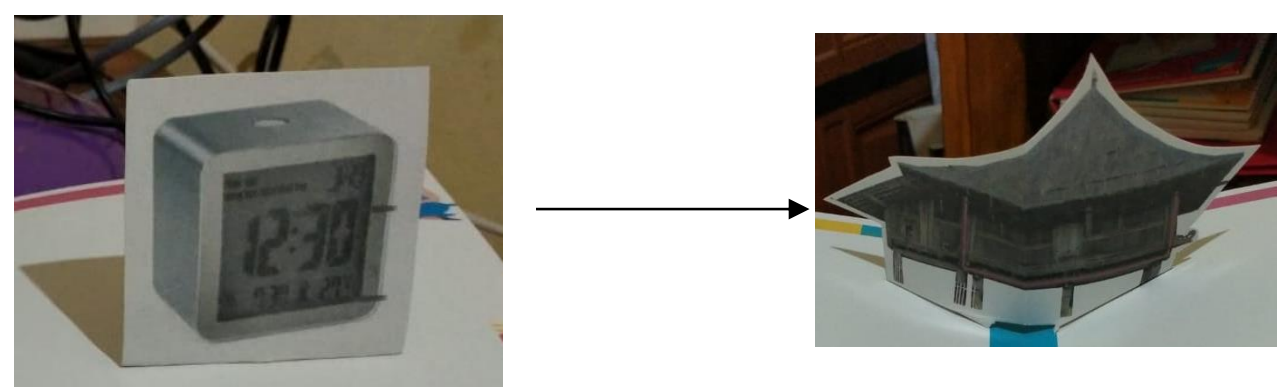

Gambar 7. Jenis Pop Up Internal Stand diganti dengan jenis V-Folding

Setelah modul diperbaiki atas saran dari para ahli, dilakukan validasi tahap 2 oleh ahli materi dan media. Pada tahap 2 ini diperoleh persentase sebesar 86,11\% dengan kriteria "Sangat Layak" oleh ahli materi dan sebesar 85,42\% dengan kriteria "Sangat Layak" oleh ahli media. Adapun hasil penilaian validasi dari ketiga validator media dan materi dapat dilihat dalam diagram berikut berikut:
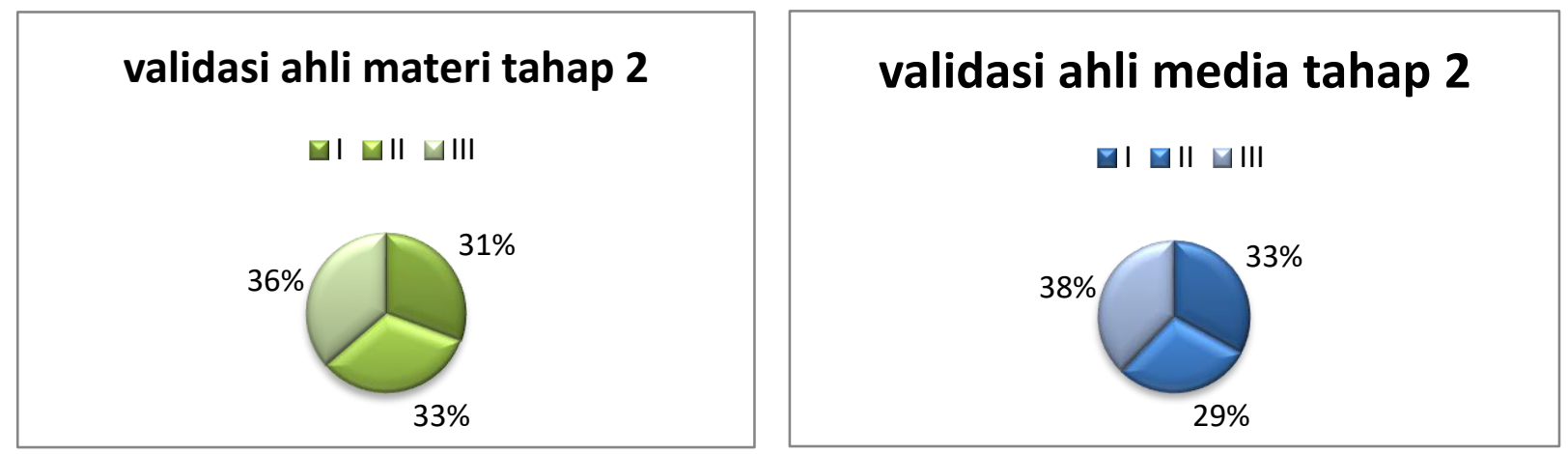

Gambar 8. Diagram Validasi Ahli Materi dan Media Tahap II

\section{Uji Lapangan Produk Utama (Main Field Testing)}

Setelah produk dinyatakan "Sangat Layak" dilakukan uji kemenarikan kepada siswa SMP N 1 Ambarawa. Aspek yang dinilai pada tahap ini diantaranya kualitas isi, ketepatan cakupan, tampilan dan bahasa. Penelitian dilakukan dengan menguji secara dua tahap yaitu uji coba dengan skala kecil dan uji coba skala besar. Uji coba skala kecil dilakukan kepada 10 siswa dari kelas VIII C SMP N 1 Ambarawa dengan persentase sebesar 86\% dengan kategori "Sangat Menarik" dan uji coba skala besar dilakukan di kelas VIII D SMP N 1 Ambarawa kepada 32 siswa dengan hasil persentase sebesar 94\% dengan kategori "Sangat Menarik".

\section{Diseminasi dan Implementasi (Dissemination and Implementation)}

Pada tahap akhir ini modul yang telah dikembangkan kemudian didistribusikan ke sekolah guna dapat membantu pembelajaran matematika di sekolah.

\section{KESIMPULAN}

Kesimpulan dari penelitian dan pengembangan ini, yakni: Penilaian validator media dan validator materi tergolong kategori "Sangat Layak" dengan nilai masing-masing 86,11\% dan 87,50\%. Pengembangan modul dengan berbasis pop up book dengan berbalut kebudayaan Lampung memperoleh 
respon dari siswa dengan persentase 94\% yang digolongkan dalam kategori "Sangat Menarik". Saran yang dapat diberikan dari hasil penelitian dan pengembangan ini yaitu: media ajar yang telah dikembangkan bisa digunakan oleh guru untuk mengatasi kesukaran dalam menjelaskan materi yang dapat sehingga menjadikan siswa dapat mandiri dalam proses pembelajaran. Modul yang digunakan peneliti dapat dimanfaatkan oleh peserta didik untuk meningkatkan minat peserta didik terhadap pembelajaran matematika khususnya pada materi bangun ruang sisi datar dan dapat digunakan dalam pembelajaran secara mandiri. Peneliti lain dapat mengembangkan media ajar berbasis pop up book agar siswa lebih tertarik untuk belajar ketika di dalam maupun di luar kelas. Dan penelitian ini dapat dijadikan referensi untuk penelitian berikutnya.

\section{UCAPAN TERIMA KASIH}

Terima kasih penulis ucapkan kepada seluruh pihak yang sudah membantu dalam terlaksananya penelitian ini. Terima kasih kepada Bapak/Ibu Dosen pembimbing, dan Bapak/Ibu dosen di Universitas Islam Negeri Raden Intan Lampung atas bimbingan, dan arahannya selama ini.

\section{REFERENSI}

Amir, M. F. (2015). Pengaruh Pembelajaran Kontekstual Terhadap Kemampuan Pemecahan Masalah Matematika Siswa Sekolah Dasar. Prosiding Seminar Nasional Pendidikan, 34-42.

Andinny, Y. (2015). Pengaruh konsep diri dan berpikir positif terhadap prestasi belajar matematika siswa. Formatif: Jurnal Ilmiah Pendidikan MIPA, 3(2).

Arifin, Z. (2012). Model Penelitian dan Pengembangan. PT. Remaja Rosdakarya.

Baiduri, B., Taufik, M., \& Elfiani, L. (2019). Pengembangan Media Pembelajaran Pop-Up Book Berbasis Audio Pada Materi Bangun Datar Segiempat Di SMP. Aksioma Jurnal, 8(1), 248-261.

Bashori, B. (2017). ANTARA BUDAYA DAN AGAMA; Menegaskan Identitas Islam Nusantara. Madania: Jurnal Ilmu-Ilmu Keislaman, 7(1), 26-56.

Borg, \& Gall. (2003). Educational Research An Introduction (ed. Tujuh). Allyn and Bacon.

Budiman, H. (2017). Peran teknologi informasi dan komunikasi dalam pendidikan. Al-Tadzkiyyah: Jurnal Pendidikan Islam, 8(1), 31-43.

Gazali, E. (2018). Pesantren di antara generasi alfa dan tantangan dunia pendidikan era revolusi industri 4.0. OASIS: Jurnal Ilmiah Kajian Islam, 2(2), 94-109.

Halisah, N. (2018). Pengembangan Media Pembelajaran Pop Up Book Guna Menunjang Penguasaan Konsep Peserta Didik Kelas X Pada Pelajaran Biologi di Tingkat SMA/MA. Universitas Islam Negeri Raden Intan Lampung.

Hartono, W., \& Noto, M. S. (2017). Pengembangan modul berbasis penemuan terbimbing untuk meningkatkan kemampuan matematis pada perkuliahan kalkulus integral. Jurnal Nasional Pendidikan Matematika, 1(2), 320-333.

Hasanah, U. (2019). Upaya pondok pesantren dalam mengembangkan Life Skill santri di Pondok Pesantren Putri Al Mawaddah Ponorogo. UIN Sunan Ampel Surabaya. 
HASANAH, U. N., Thahir, A., Komaruddin, K., \& Rahmahwaty, R. (2019). MURDER Learning and Self Efficacy Models: Impact on Mathematical Reflective Thingking Ability. Journal for the Education of Gifted Young Scientists, 7(4), 1123-1135.

Hermawan, H., \& Md, A. (N.D.). Perlindungan Hukum Terhadap Kekayaan Intelektual Ekspresi Budaya Tradisional Berdasarkan Pasal 38 Undang-Undang Nomor 28 Tahun 2014 Tentang Hak Cipta Di Kalimantan Barat. Jurnal Hukum Prodi Ilmu Hukum Fakultas Hukum Untan (Jurnal Mahasiswa S1 Fakultas Hukum) Universitas Tanjungpura, 4(4).

Irawaan, A. (2015). Pengaruh kecerdasan numerik dan penguasaan konsep matematika terhadap kemampuan berpikir kritik matematika. Formatif: Jurnal Ilmiah Pendidikan MIPA, 4(1).

Irvaniyah, I., \& Akbar, R. O. (2014). Analisis Kecerdasan Logis Matematis dan Kecerdasan Linguistik Siswa Berdasarkan Jenis Kelamin (Studi Kasus Pada Siswa Kelas XI IPA MA Mafatihul Huda). Eduma: Mathematics Education Learning and Teaching, 3(1).

Maftukhin, M. (2015). Ilmuwan, Etika Dan Strategi Pengembangan Ilmu Pengetahuan Di Indonesia. Epistemé: Jurnal Pengembangan Ilmu Keislaman, 10(1), 199-226.

Majid, M. K. (2019). Angka Nol sebagai Kontribusi Muslim terhadap Matematika Modern. Kalimah: Jurnal Studi Agama Dan Pemikiran Islam, 17(1), 5-27.

Muhammad, M., \& Nurdyansyah, N. (2015). Pendekatan pembelajaran saintifik. Nizamia Learning Center.

Nugraha, H. (2019). Perpustakaan Dan Pelestarian Kebudayaan. UNILIB: Jurnal Perpustakaan, 40(1), $50-62$.

Nurfitriyanti, M. (2016). Model Pembelajaran Project Based Learning Terhadap Kemampuan Pemecahan Masalah Matematika. Formatif: Jurnal Ilmiah Pendidikan MIPA, 6(2).

Nurwahidah, S. (2018). Pengembangan Media Pembelajaran Pop Up Book Terintegrasi Ayat-Ayat AlQura'an Pada Materi Suhu dan Perubahannya. Universitas Islam Negeri Raden Intan Lampung.

Permata, Rizki Septi, Abi Fadila, and Ida Fiteriani. 2018. "PENGEMBANGAN BAHAN AJAR MATEMATIKA PADA MATERI BANGUN RUANG SISI DATAR MENGGUNAKAN SOFTWARE." Prosiding: Seminar Nasional Matematika dan Pendidikan Matematika UIN Raden Intan Lampung 1(2): 565-72.

Paradita, Y., \& Sukasno, W. R. (2016). Penerapan Strategi THINK-TALK-WRITE (TTW) Terhadap Kemampuan Pemahaman Konsep Matematika Siswa Kelas VIII SMP Negeri Muara Beliti Tahun Pelajaran 2016/2017. Artikel Ilmiah STKIP-PGRI Lubuklinggau.

Prasetyo, B., \& Trisyanti, U. (2018). Revolusi Industri 4.0 dan Tantangan Perubahan Sosial. IPTEK Journal of Proceedings Series, 5, 22-27.

Priatmoko, S. (2018). Memperkuat Eksistensi Pendidikan Islam di Era 4.0. TA'LIM: Jurnal Studi Pendidikan Islam, 1(2), 221-239.

Rinaldi, Achi, Rany Widyastuti, and Siti Mardiah. 2018. "Pengembangan Modul Pembelajaran Matematika Berbasis Etnomatematika Menggunakan Metode Inkuiri." Desimal: Jurnal Matematika 1(2): 119-26.

Romadon, B. (2020). Penguatan Pendidikan Matematika Dalam Menunjang Persiapan Sdm Yang Unggul Menuju Indonesia Maju. PROCEEDING. 
Sanjaya, W. (2015). Penelitian Pendidikan (Jenis, Metode dan Prosedur). PRENADAMEDIA GROUP.

Santiana, N. L. P. M., Sudana, D. N., \& Garminah, N. N. (2014). Pengaruh Model Pembelajaran Kooperatif Tipe Numbered Heads Together (NHT) Terhadap Hasil Belajar Matematika Siswa Kelas V Sekolah Dasar di Desa Alasangker. MIMBAR PGSD Undiksha, 2(1).

Setiawan, I. N. A. F., Noorwatha, I. K. D., Udayana, A. A. G. B., Wasista, I. P. U., Jayanegara, I. N., Aditama, P. W., Yasa, I. W. A. P., Yasa, N. P. D., Anggara, I. G. A. S., \& Setiawan, I. K. (2020). Kapita Selekta Citraleka Desain 2020: Dialektika Seni, Desain, dan Kebudayaan Pada Era Revolusi Industri 4.0. STMIK STIKOM Indonesia.

Sujati, B. (2018). Sejarah Perkembangan Globalisasi dalam Dunia Islam. NALAR: Jurnal Peradaban Dan Pemikiran Islam, 2(2), 98-109.

Wahyuni, A., Tias, A. A. W., \& Sani, B. (2013). Peran etnomatematika dalam membangun karakter bangsa. Makalah Seminar Nasional Matematika Dan Pendidikan Matematika, Prosiding, Jurusan Pendidikan Matematika FMIPA UNY, Yogyakarta: UNY.

Winarso, W. (2014). Membangun Kemampuan Berfikir Matematika Tingkat Tinggi Melalui Pendekatan Induktif, Deduktif dan Induktif-Deduktif dalam Pembelajaran Matematika. Eduma: Mathematics Education Learning and Teaching, 3(2).

Winataputra, U. S., Delfi, R., Pannen, P., \& Mustafa, D. (2014). Hakikat Belajar dan Pembelajaran. Hakikat Belajar Dan Pembelajaran, 1-46.

Zahara, A. C., Hastari, R. C., \& Maâ, H. F. (2017). Analisis Kesalahan dalam Menyelesaikan Soal pada Materi Lingkaran Ditinjau dari Gaya Kognitif Siswa Kelas VIII SMP Negeri 1 Pogalan Semester Genap Tahun Pelajaran 2015/2016. INSPIRASI (JURNAL ILMU-ILMU SOSIAL), 13(3). 